\title{
JUGANDO CON PERSONAJES LITERARIOS
}

\author{
Emilio Chinchilla Rodríguez \\ Asesor Nacional en Macroevaluación, Dirección de Gestión y \\ Evaluación de la Calidad, Ministerio de Educación Pública \\ San José, Costa Rica
}

Recibido 3-IV-2009 • Aceptado 12-V-2009 • Corregido 15-VI-2009

Resumen: El artículo hace una propuesta innovadora para la aplicación de la técnica de "Juego de Roles" en la enseñanza de la literatura, que permite un acercamiento de los estudiantes a los textos de lectura obligatoria y otros, convirtiéndolos en lectores profundos y críticos, y en auténticos promotores de lectura.

Palabras clave: Juego de roles, enseñanza de la literatura, técnicas innovadoras, didáctica de la lectura.

Abstract: The article makes an innovative proposal for the application of the technique "Game of Roles" in teaching Literature that allows students approach texts of mandatory reading and others, turning them into deep and critical readers, and authentic promoters of reading.

Key words: Game of roles, innovating education of literature, techniques, didactics of reading.

\section{Introducción}

El juego de roles es una estrategia didáctica de carácter lúdico que, como establece Vargas (1992), busca analizar las diferentes actitudes y reacciones de las personas frente a situaciones o realidades concretas. Según la autora, esta estrategia consiste en "...una actuación en la que se utilizan gestos, acciones o palabras" (p. 25).

En esta dinámica se intenta representar actitudes, características y habilidades de las personas, sus ocupaciones, formas de ver el mundo y las relaciones entre ellas. Puede ser útil, señala Vargas (1992), para iniciar el estudio de un tema, profundizar en un aspecto de una cuestión que se esté enseñando o finalizar el estudio de una temática para representar la conclusión.

Siguiendo a Baquerizo (2007), pese a que se cree que esta estrategia pedagógica es meramente improvisada, ella requiere un adecuado planeamiento y un trabajo sistemático, es decir, que si bien es una actividad en la que lo espontáneo importa, también hay que realizar un planeamiento al respecto.

Una ventaja para aplicar esta actividad, de acuerdo con Baquerizo (2007), es que la “...temática de los 
juegos de roles es infinita, debido a que depende de la capacidad imaginativa del profesor, especialmente y de los alumnos, quienes tienen que decidir y desarrollar las actividades de aprendizaje" (p. 1).

Es de importancia pedagógica, puesto que motiva el aprendizaje y permite crear un ambiente de enorme participación en el diálogo o debate posterior, sobre todo cuando el grupo se siente implicado en lo que se dramatiza. Directamente, permite desarrollar el lenguaje oral, gestual y mímico. Además, "Convierte el juego en una forma de expresión y en un instrumento de investigación y de trabajo" (Baquerizo, 2007, p. 2).

La propuesta innovadora que se plantea aquí pretende implementar el uso de la técnica llamada "Juego de roles" en la enseñanza de la literatura, para proveer mayor dinamismo en el trabajo de aula, así como para incentivar la creatividad y deseos de investigación en el estudiante.

Las formas de trabajarla son infinitas, pero en este documento se da el detalle de algunas de sus posibilidades.

\section{Propuestas de Aplicación}

\section{- Fiesta de Personajes}

Consiste en que cada uno de los discentes de una sección, incluyendo o no a su profesor, representan un personaje de una obra literaria (si es una obra pequeña pueden usarse otros textos conjuntos). El escenario en el que lo harán consiste en una supuesta fiesta, en la que cada uno deberá ir presentándose. En el transcurso de la fiesta podrán irse contando historias y expresando opiniones, de acuerdo con los sentimientos e ideas de los supuestos personajes. También, podrá haber confrontaciones si alguna posición acerca de un tema resulta controvertida o polémica.

\section{- Reunión entre Personajes}

Al igual que en el caso anterior, los educandos de un grupo asumen un papel de un texto literario o tema conexo. La actividad reside en la participación en una reunión o concejo donde se hace el relato de temas de importancia para todos los personajes. El aula se organizaría en círculo o se puede destacar una sección del salón de clases, para un personaje que guíe la reunión.

\section{- Entrevistando a un personaje}

A uno o varios de los estudiantes de un grupo les corresponde asumir un papel de una obra literaria. Los demás deben actuar como si fuesen periodistas y realizar una entrevista al personaje en particular. Esto lo pueden realizar de dos formas: como si estuviesen en una conferencia de prensa en la que, por turnos, se les va dando la posibilidad de preguntar o por entrevistas individuales.

\section{- Conociendo la historia}

Un estudiante representa a un personaje literario que viene a contar su historia. Para ello, se sienta frente a la clase o en medio de un círculo en el aula y relata sus vivencias. Como alternativa, puede darse que no venga un personaje literario exacto, sino que lo haga, por ejemplo, un amigo, que no se mencionó en el texto, o un hermano, o padre, etc.

\section{- Cambiando de tiempo}

Uno o varios alumnos representan a un grupo de personajes literarios de una determinada época, lejana a la actual, los cuales se ven enfrentados a vivir en el momento presente. Cada uno de ellos, ya sea por preguntas de sus compañeros o iniciativa propia, evidencia los contrastes de los diferentes períodos de la historia, así como su forma de ver el mundo. Pueden presentarse maravillados ante lo que observan del momento u horrorizados. Entre las múltiples posibilidades de su realización, 
también está el hecho de que haya discusiones sobre cuál época es mejor y por qué.

\section{- $\quad$ Rescribiendo la historia}

Consiste en que cada personaje representado, ya sean pocos o muchos, tenga la intención de cambiar el desarrollo o desenlace de una historia literaria y llevarla hacia un nuevo camino. También puede estructurarse que algunos de los personajes se resistan a modificar lo que va a suceder.

\section{- $\quad$ El juicio}

Uno o varios personajes literarios representados demandan a otros caracteres o a un autor por diversos hechos. Se realiza un juicio, que al igual que los reales, contará con un fiscal, abogado defensor, jueces y demás miembros de la corte.

\section{Consideraciones para su aplicación}

La aplicación de esta estrategia didáctica no es difícil, pero requiere tener en cuenta que:

- $\quad$ Se debe conocer la situación socioeconómica de los estudiantes, para saber qué materiales solicitar a los jóvenes.

- $\quad$ Hay que tener claro el nivel y edad de los discentes para determinar que demandar de ellos, en relación con lo investigativo, la parte creadora y el conocimiento que se busca desarrollar.

- Debe existir gran flexibilidad para rectificar sobre la marcha cuando sea necesario.

\section{Metodología}

Para realizar esta estrategia lúdica se propone seguir los siguientes pasos:

\subsection{Selección de Tema}

Este puede ser escogido en su totalidad por el docente, por los estudiantes o por ambas partes. Debe tenerse esmero y calma para que el planteamiento de este sea lo suficientemente rico y vasto para la clase o las clases que se plantearán.

\subsection{Motivación, descripción, y reglas}

Después de la etapa anterior, ésta es vital. El educador debe explicar a los alumnos con suma claridad la actividad por realizar. Su misión residirá en incentivar de la mejor manera a todos ellos.

Luego de esto, el docente debe plantear las reglas del juego, pues como toda actividad debe tenerlas. Además, debe proveer la forma en que se evaluará el trabajo.

\subsection{Escogencia de Personajes}

La selección de roles puede llevarse a cabo de varias maneras. Puede ser por rifa, selección propia del docente, escogencia directa del alumno, entre otras. Para ello, el profesor debe considerar las potencialidades de sus estudiantes, así como su edad y relaciones sociales.

\subsection{Trabajo Preparatorio}

Todo juego de roles implica, no importa la profundidad del contenido a desarrollar, una labor previa de investigación y reflexión. Para ello, el educador debe definir muy claramente los contenidos y objetivos a tratar, para que así la estrategia se desarrolle de la mejor forma posible.

\subsection{Representación de Roles}

El paso cumbre es este. Cada uno de los alumnos intenta personificar su 
rol, esforzándose al máximo, para obtener el mejor provecho cognitivo de la actividad. El docente, en este punto, es pieza clave como el guía hacia un aprendizaje significativo, de una forma atrevida, diferente, creativa.

\subsection{Debate}

Después de realizada la representación es conveniente que el educador escuche la opinión de los estudiantes sobre lo acontecido. También, es adecuado que el educador externe lo que piensa, teniendo cuidado de resaltar lo positivo y que al mencionar algo negativo, se establezca cómo mejorarlo, para de esta forma concretar en una próxima ocasión la actividad de mejor manera.

\section{Materiales}

En el juego de roles, dependiendo lo que se vaya a trabajar, puede requerirse los siguientes materiales:

- Vestuario variado

- Radiograbadoras

- Pupitres

- Pizarra

- Hojas blancas impresas

- Cartulinas

- Papel de construcción

- Ilustraciones, fotografías

- Materiales varios como escobas, palillas, entre muchos otros.

\section{Tiempo}

El juego de roles se presta más para su ejecución en tiempos largos ininterrumpidos, que podrían ser de dos o tres lecciones, es decir, de ochenta a ciento veinte minutos. También, puede extenderse, si es necesario; pero se debe tener muy claro qué se quiere lograr con ello y cómo se va a alcanzarlo.

\section{Evaluación}

Como parte del proceso de enseñanza-aprendizaje, la parte evaluativa es fundamental. Para el caso del Juego de Roles deben dimensionarse dos esferas. Visualicemos la primera. Se refiere básicamente al valor del trabajo de los alumnos. Para esto, es necesario, clarificar el componente en el cual se va a evaluar la participación de los educandos en dicha actividad, ya sea como un trabajo cotidiano, extraclase o incluso, como una prueba de ejecución. Indiferentemente de cuál sea, se deben plantear los aspectos específicos a evaluar, de acuerdo con el juego roles indicado.

Si bien cada juego de papeles es único, hay aspectos que pueden calificarse en cualquier situación, por ejemplo: la impostación de la voz, el vestuario (sí se requiriese), dominio del rol, creatividad, interacción con otros personajes, entre otros.

Para la asignación de la nota es conveniente elaborar una escala que contemple una variada gama de cumplimiento, de forma que la evaluación sea lo más objetiva posible.

La segunda postura, con respecto a la evaluación, se refiere a la observación de los datos positivos y negativos sobre la actividad realizada, información proporcionada por los estudiantes y lo visualizado por el educador. La finalidad obvia de esta parte es que para un caso venidero, la estrategia sea aún más fructífera.

\section{Ejemplos de posible aplicación}

A continuación se muestra unas aplicaciones de la estrategia didáctica aplicada a un tema muy concreto. 


\subsection{El concilio de los dioses griegos y romanos}

En décimo y undécimo año en la materia de Español, se trabaja con textos literarios de la antigüedad griega y romana. Para entender estas obras es necesario conocer sobre el contexto social, cultural, económico y religioso en el cual fueron creadas. Uno de los aspectos que debe tomarse en cuenta para esto es la Mitología Grecorromana. $\mathrm{Su}$ estudio es apasionante; sin embargo, la forma en que se enseña (si es que se hace) es común que sea estrictamente teórica. Ello las convierte ante los educandos en poco llamativos e interesantes. Para cambiar esta desesperanzadora visión, podría emplearse un juego de roles como el que se propone.

La actividad para desarrollar temas de esa índole consiste en simular una reunión entre dioses griegos y otras divi- nidades. Cada educando representa un personaje, que tiene como misión presentarse, contar una historia sobre su vida e interactuar cuando otros cuentan las propias, negando cosas o afirmándolas, entre muchas otras posibilidades. Para realizar el papel, se debe investigar bibliografía brindada por el docente. Asimismo, deberán vestirse de acuerdo con las características del personaje ${ }^{1}$.

El aula se dispone en círculo para la actividad. Por todo el lugar se colocan objetos de la cultura griega e imágenes alusivas al tema, para motivar la lección. El tiempo para realizar la actividad es de dos lecciones, es decir, ochenta minutos.

Para seleccionar el rol de cada discente, se realizaría una rifa.

La labor de cada estudiante se conceptuaría como un trabajo extraclase, que se podría evaluar empleando la Tabla 1:

Tabla 1

Escala para evaluar el trabajo del estudiante en el juego de roles llamado "El concilio de dioses griegos y romanos"

\begin{tabular}{|c|c|c|c|c|c|c|}
\hline \multirow{2}{*}{\multicolumn{2}{|c|}{ Rubros por evaluar }} & \multicolumn{5}{|c|}{ Valor } \\
\hline & & 1 & 2 & 3 & 4 & 5 \\
\hline \multicolumn{2}{|c|}{$\begin{array}{l}\text { 1. Impostación de la voz: su voz es escuchada con claridad en el } \\
\text { recinto y con clara dicción. }\end{array}$} & & & & & \\
\hline \multicolumn{2}{|c|}{$\begin{array}{l}\text { 2. Vestuario escogido: seleccionó elementos que lo identifican cla- } \\
\text { ramente con el personaje asignado. }\end{array}$} & & & & & \\
\hline \multicolumn{2}{|c|}{ 3. Gestos y acciones: intenta actuar como el personaje. } & & & & & \\
\hline \multicolumn{2}{|c|}{$\begin{array}{l}\text { 4. Dominio del tema: expresa su caracterización como personaje } \\
\text { manifestando amplio conocimiento sobre el mismo. }\end{array}$} & & & & & \\
\hline \multicolumn{2}{|c|}{$\begin{array}{l}\text { 5. Dinámica de participación: interviene en el momento e instante } \\
\text { solicitado, sin dilación. }\end{array}$} & & & & & \\
\hline \multicolumn{2}{|c|}{$\begin{array}{l}\text { 6. Investigación: acude a diversas fuentes investigando sobre el } \\
\text { personaje asignado y la cultura en la que se envolvió. }\end{array}$} & & & & & \\
\hline \multicolumn{2}{|r|}{ Total } & & & & & \\
\hline Simbología & $\begin{array}{l}\text { 1: Muy malo } \\
\text { 2: Malo } \\
\text { 3: Regular } \\
\text { 4: Bueno } \\
\text { 5: Muy bueno }\end{array}$ & & & & & \\
\hline
\end{tabular}

Para calcular la nota obtenida en el trabajo extraclase, se aplicará la regla de tres:

$$
\text { Nota }=\frac{\text { Total de puntos obtenidos x } 100}{30}
$$




\subsection{Yo soy Arturo Cova}

Se indica con anterioridad a los jóvenes, que en una fecha determinada recibirán la visita de un personaje importante, que tendrán como labor anotar las cosas que dirá este señor, así como plantear preguntas sobre lo dicho. El día citado, el docente se vestirá, o adecuará su vestuario al del personaje Arturo Cova, de la novela La vorágine. Este entrará al aula, como todos los días, y realizará las actividades de cotejo. Luego, indicará que la persona que vino a dar la charla, ya está allí. Se llama Arturo Cova, les dirá. Les explicará que para poder mostrarse usará su cuerpo. Al decir esto, el docente explicará que se trata de un juego.

Momentos después el profesor se colocará al frente del grupo, como Arturo Cova. El personaje empezará contando aspectos de su historia, luego interactuará con los jóvenes. Posteriormente, este declarará que se ha retirado.

En este caso la actividad tiene un fin de motivación de lectura., y se les puede solicitar un informe sobre lo dicho por el personaje. Este se puntuaría como trabajo cotidiano, o extraclase, de acuerdo con el lugar donde se realice.

\subsection{Fiesta de personajes de undécimo}

Como una forma de repasar sobre los textos leídos de undécimo y décimo año, puede realizarse este juego de roles. Se les pedirá a los jóvenes que escojan un personaje protagonista de cualquiera de los textos leídos en el transcurso de los dos años. Para ello, se realizará una rifa.

Cada estudiante deberá repasar la historia, así como las características de su personaje y su relación con los otros. A cada uno le tocará jugar el rol de su personaje, para lo cual ocuparán vestuario y otros elementos que los identifiquen como tales. Lo harán en una actividad que simulará ser una fiesta y para la cual, se organizarán trayendo bocadillos y bebidas. Como se evidencia, consistirá en una actividad de esparcimiento y de aprendizaje.

El día del evento, cada discente deberá hablar con al menos cinco personajes. En una hoja que cada uno elaborará, irá anotando los aspectos físicos de ese personaje con el que hablará. Además le pedirá que firme. Cada estudiante estampará la firma del personaje que representan. Mientras se va dando todo esto, comerán los bocadillos y bebidas que llevaron para la ocasión.

El trabajo se valorará como extraclase, y podría calificarse de acuerdo con la Tabla 2. (Ver Tabla 2 en la siguiente página).

\section{Conclusiones}

La enseñanza de la literatura requiere de propuestas que permitan superar los bajos índices de lectura en secundaria y la pobre capacidad analítica de los educandos. La problemática de este asunto no es per se, de ahí su importancia. Sabemos bien que un discente con altas destrezas lectoras, tanto en lo profuso como en lo profundo, es un estudiante que puede desempeñarse mucho mejor en otras áreas y con ello, sacar más partido, cognitivamente hablando.

Las técnicas tradicionales de abordaje de la literatura, así como el acercamiento metodológico a los textos ${ }^{2}$ que se han implementando en nuestras aulas no han conseguido subsanar la cuestión en sí, habría que ver si no la han agravado, más bien. A esto se suma el hecho de que la actualidad tecnológica presenta muchas opciones de competencia con el medio literario, que visualizan al texto como un objeto desfasado, desechando todas sus capacidades de desarrollo.

La única manera de atacar el problema es convertir a la obra literaria en un objeto de deseo y disfrute para el estudiante, en una posibilidad de aprender no aburrida, que exige mucho de sí, pero 
Tabla 2

Escala para evaluar el trabajo del estudiante en el juego de roles denominado

"Fiesta de personajes de Undécimo"

\begin{tabular}{|c|c|c|c|c|c|}
\hline Rubros a evaluar & 1 & 2 & 3 & 4 & 5 \\
\hline $\begin{array}{l}\text { 1. Adaptación física del personaje: busca acoplarse a las caracte- } \\
\text { rísticas del ser ficticio. }\end{array}$ & & & & & \\
\hline 2. Entrevistas con personajes: cumple con el número solicitadas. & & & & & \\
\hline 3. Caracterización de contenido del personaje. & & & & & \\
\hline $\begin{array}{l}\text { 4. Orden y Aseo en la Actividad: participa sin alterar ninguno de } \\
\text { estos aspectos. }\end{array}$ & & & & & \\
\hline $\begin{array}{l}\text { 5. Participa en la organización del evento: se interesa en los } \\
\text { aspectos organizativos y aporta los elementos necesarios para } \\
\text { la realización de este mismo. }\end{array}$ & & & & & \\
\hline Total & & & & & \\
\hline
\end{tabular}

Simbología $\left[\begin{array}{l}\text { 1: Muy malo } \\ \text { 2: Malo } \\ \text { 3: Regular } \\ \text { 4: Bueno } \\ \text { 5: Muy bueno }\end{array}\right.$

Para calcular la nota obtenida en el trabajo extraclase, se aplicará la regla de tres:

Nota $=\frac{\text { Total de puntos obtenidos } \mathrm{x} 100}{25}$

que brinda mucho más que cualquier otro medio. Además, que el trabajo con las obras literarias no sea una canción a la monotonía, una repetición y clasificación de conceptos, sino una expresión de apertura, de discusión de ideas.

La propuesta del Juego de Roles busca vincular a los jóvenes por medio de la técnicas lúdicas con los textos literarios, para que los vivan internamente y encuentren el gusto por la lectura, para que se conviertan en verdaderos promotores, no solo de la literatura, sino del aprendizaje en general.

\section{Notas}

1 También pueden emplearse máscaras, o simples imágenes sobre los personajes.
2 Cuando hablamos de acercamiento metodológico nos referimos a los conceptos de análisis literarios implementados para estudiar la textualidad. En mi criterio, en los últimos años, las investigaciones sobre las obras literarias en nuestros colegios se han convertido en un recabamiento de datos superficiales, meramente accesorios.

\section{Referencias bibliográficas}

Baquerizo, A. (2007). Técnica del juego de roles. Consultado el 4 de abril de 2007 de http//www.isph.edu. pe/Materiales\%20 ducativos/ Juego\%\%20de\%roles.pdf

Vargas, L. (1992). Técnicas participativas para la educación popular. San José: Estudios y Publicaciones Alforja. 
